\title{
Human Prenatal Investment Affected by Maternal Age and Parity
}

\author{
Francisco Braza ${ }^{1}$
}

This paper investigates the effects of mother's age and parity on the prenatal allocation of resources in sons and daughters using a sample of 6994 in 20to 34-year-old mothers from Granada (Spain). This study tests the TriversWillard allocation model, which predicts that, depending on the mother's condition, there can be a bias from 50/50 expected investment in the sexes. The results show that mothers of 25-29 age class produce relatively heavier sons compared to younger mothers, suggesting a bias in the allocation of resources before birth favoring neonate boys. This extra investment in boys appears to be related more to the mother's age than to her parity. Offspring of multiparous mothers had shorter gestation length, but multiparous mothers of the 25-29 age class had boys with a longer gestation than the younger ones. The 25-29 age class mothers are in the peak of fertility and they are presumably in better condition than the other mothers in the study sample. The results suggest that Granada women performed a sex-biased prenatal investment favoring sons by prolonging the gestation period. An index of boys' extra birth weight is proposed as a suitable variable to measure the maternal prenatal investment.

KEY WORDS: Spanish women; extra birth weight; maternal effects; gestation length; TriversWillard model.

\section{INTRODUCTION}

Trivers and Willard's model (Trivers and Willard, 1973) predicts that a male in good condition at the end of the period of parental investment is expected to outreproduce a sister in similar condition, while she is expected

\footnotetext{
${ }^{1}$ Estación Biológica de Doñana, CSIC, Avda. Ma Luisa s/n, Pab. del Perú, 41013 Sevilla, Spain. E-mail: braza@ebd.csic.es.
} 
to outreproduce him if both are in poor condition. Trivers and Willard conclude that if the model is correct, natural selection favors deviation away from 50/50 investment in the sexes, rather than deviations in sex ratio per se. According to this, a variation in the allocation of resources by mothers to their offspring in the prenatal investment period might be expected.

As Trivers and Willard pointed out, the application of their model to humans is complicated by the tendency of males to invest parental effort in their young (which reduces variance in male reproductive success), and by the importance of kin interactions among adults. Nevertheless, the applicability to humans of some variants of Trivers and Willard's model is a topic that has attracted the interest of human reproductive studies (Daly and Wilson, 1999). Most of the studies have focused on the aspects of the model related to the variation in the sex ratio at birth. Less common are those studies which focused on the differential allocation of resources during the prenatal period (for a revision, see Chacon-Puignau and Jaffe, 1996).

For mammals, several authors (Anderson and Fedack, 1987; Birgersson and Ekvall, 1997; Festa-Bianchet, 1988; Fletcher, 1971; Lee et al., 1991; Pélabon et al., 1995) have pointed out that the mother's prenatal effort (birth weight) is more representative of maternal expenditure than postnatal effort (postnatal growth or suckling performance), and Voland (1998) points out that under stable living conditions there is frequently a monotonic relation between effort and investment.

A study of Polish infants (Hauspie et al., 1996) indicates that the body size of children at birth, that is, the outcome of prenatal growth, is largely controlled by intrauterine factors, reflected by maternal physical rather than genetic factors (no relation with father's stature).

A likely indicator of variation in the condition of the mother could be her reproductive experience, since there is evidence pointing to variation in the intrauterine environment caused by the number of previous childbirths. Women of higher parity have more vascularized uteri, which leads to infants of higher birth weight (Rybo et al., 1985). In a study of Spanish women, multiparous mothers gave birth to heavier boys than girls, whereas for primiparous mothers, there was no significant sexual difference in children's birth weight (San José et al., 1997). This result is consistent with the hypothesis of relatively higher costs of prenatal investment for primiparous women with respect to multiparous ones.

Another source of variation in the condition of the mother could be her age. Stein (1985) pointed out the existence of a relation between maternal age and birth weight through intrauterine environment, with mothers of a younger and older age being strongly linked to higher rates of low birth weight. More recently, the results of Bereczkei et al. (2000) confirm that maternal age has a significant effect on birth weight. 
The aim of this study is to examine the effects of maternal age and parity on the sex biases in the allocation of resources before birth in order to test the following predictions of Trivers and Willard's model:

1) In human societies, or at least in contemporary occidental populations, a sex bias in the allocation of resources before birth is likely according to the mother's condition.

2) Taking into account that maternal age is a source of variation in the mother's condition, a differential investment in the prenatal period according to the mother's age would be expected, independently of her parity (previous reproductive experience); with boys of mothers in better condition being proportionately heavier than those from mothers in worse condition.

3) Considering parity as an indicator of the mother's condition, a variation in the sex-biased prenatal investment related to the previous reproductive experience of mothers, independently of their age, is also likely. Hence, boys from multiparous mothers would be proportionately heavier than those from primiparous ones.

To explore the potential effects of the mother's age and parity on the differences in prenatal growth rates, it is necessary to consider both the birth weight and the duration of the gestation period. Therefore, we will also focus on the relations between age and previous reproductive experience of the mothers and gestation length (duration of prenatal investment).

\section{METHODS}

The data analyzed in this paper were obtained from hospitals of the Servicio Andaluz de Salud (Andalusian Health Service), which provided us with data of all the births $(n=13475)$ registered during 1992-1994 in Granada County (southern Spain). Taking into account the aims of this study we homogenized the sample according to the selected variables. From the data, only natural births and within these, live births were considered. Neither caesarean sections nor preterm births (under 35 weeks of gestation) have been considered. Mothers of twins were also removed because twins are probably very costly to their mothers, thus producing atypical maternal reproductive patterns (Gaulin and Robbins, 1991). We have also discarded data on those mothers that suffered any risk factor, such as previous uterine surgem (sterility treatment), illness (diabetes, toxemia, anemia), tobacco habit, alcoholism, drug addiction, and/or social or psychological problems. Data on those with factors related to neonatal morbidity, such as traumatisms, congenital illness, and anomalies in the central and peripheric nervous system of the fetus, or fetus suffering during labor (anoxia) were 


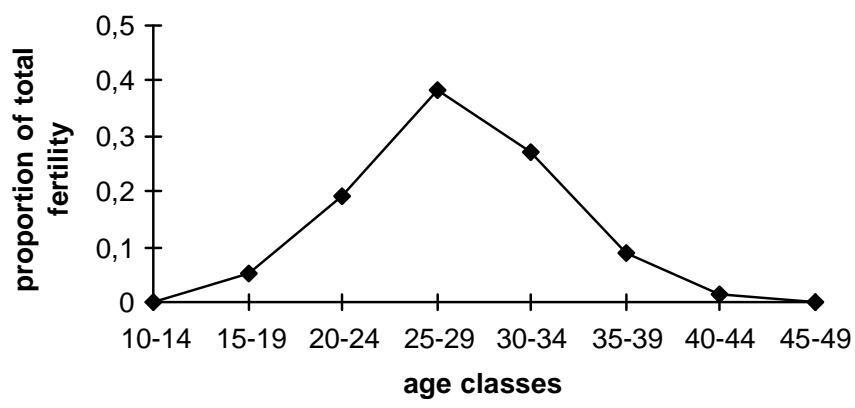

Fig. 1. Proportion of total fertility contributed by each age class of Granada women.

also discarded. Granada's mothers from 14 to 49 years of age $(n=8572)$ were used to obtain the proportion of the total fertility contributing at each age (Fig. 1).

We only considered 20- to 34-year-old mothers and those with less than three previous childbirths for the reminder of the study. The number of older primiparous and younger multiparous mothers was limited, and it was not possible to evaluate the separate effect of primiparous mothers versus mothers with one or two previous childbirth in younger and older women. The sample size can be seen in Table I. The variables considered in this study are the following:

Table I. Study Sample Sizes for Each of the Categories Considered

\begin{tabular}{lcccc}
\hline $\begin{array}{l}\text { Mother's age } \\
\text { class }\end{array}$ & $\begin{array}{c}\text { Mother's } \\
\text { parity }\end{array}$ & $\begin{array}{c}\text { Sex of the } \\
\text { neonate }\end{array}$ & $\begin{array}{c}\text { Birth weight } \\
\text { data }\end{array}$ & $\begin{array}{c}\text { Gestation } \\
\text { length data }\end{array}$ \\
\hline $20-24$ & 0 & girls & 592 & 578 \\
& 0 & boys & 610 & 600 \\
& 1 & girls & 183 & 181 \\
& 1 & boys & 184 & 181 \\
& 2 & girls & 19 & 18 \\
$25-29$ & 2 & boys & 34 & 34 \\
& 0 & girls & 912 & 907 \\
& 0 & boys & 981 & 974 \\
& 1 & girls & 527 & 523 \\
$30-34$ & 1 & boys & 531 & 529 \\
& 2 & girls & 102 & 100 \\
& 2 & boys & 128 & 125 \\
& 0 & girls & 432 & 429 \\
& 0 & boys & 458 & 452 \\
& 1 & girls & 438 & 436 \\
& 1 & boys & 449 & 443 \\
& 2 & girls & 193 & 188 \\
& 2 & boys & 221 & 219 \\
& & & 6994 & 6917 \\
\hline
\end{tabular}




\section{A) Independent Variables}

1) Parity (number of previous childbirths). Three categories were considered: (a) parity 0 (or primiparous) when the mother had a child for the first time; (b) parity 1, including mothers with a single previous child; and, (c) parity 2, mothers with two previous childbirths.

2) Mother's age. In the same way as other authors (see Hammel, 1996), we considered mother's age grouped in 5-year classes.

We used age and parity as a categorical instead of ordinal variable since a lineal relation between them and the other variables (birth weight and gestation length) might not be expected.

3) Sex of the neonate.

\section{B) Dependent Variables}

4) Boys' extra birth weight. In order to examine the effects of the mother's age and parity on the variance in maternal sex-biased prenatal investment and taking into account the sexual differences in human birth weight (an analysis of 70505 Spanish neonates points out that neonate boys are heavier than neonate girls (Verdú et al., 1998), an index of the extra investment by mothers in birth weight of boys is proposed. The index is obtained calculating the difference between the birth weight of each boy and the mean birth weight of girls for the same mother's age class and parity. The weight of the neonates (in grams) was obtained at the moment of birth.

5) Gestation length in weeks. In accordance with the last menstruation and with the corrections made by means of sonograms before the 20th week of gestation.

ANOVAs were applied to obtain the variation of the boys' extra birth weight and gestation length in relation to each variable (mother's age, parity, and sex of the neonate), studying the effect of each separate variable and the interaction among them (Super ANOVA, Abacus Concepts, Inc., 19891991). The comparisons of the different factors values were analyzed through post hoc tests (Scheffe's S). All tests were two tailed.

\section{RESULTS}

As expected, a positive significant correlation exists between mother's age and parity in the study sample $(n=6994, r=0.291, p=0.0001)$, and 
Table II. Analysis of Variance Concerning the Extra Birth Weight of Boys of Mothers of Different Parity and Age Class

\begin{tabular}{lrrrc}
\hline \multicolumn{1}{c}{ Source } & \multicolumn{1}{c}{ df } & Mean square & $F$ value & $p$ value \\
\hline Age class & 2 & 1343243.142 & 7.070 & 0.0009 \\
Parity & 2 & 241318.044 & 1.270 & 0.2809 \\
Age class $\times$ Parity & 4 & 426330.170 & 2.244 & 0.0619 \\
Residual & 3587 & 189996.662 & & \\
\hline
\end{tabular}

boys were heavier than girls at birth averaged over the age class and parity of their mothers $\left(F_{(2,6991)}=34.937, p=0.0001\right)$.

The mothers' age class contributed significantly to the variance of the extra birth weight of boys, independently of the mother's parity (Table II); mothers of the 25-29 age class gave birth to boys proportionally heavier than the mothers of the $20-24$ age class $\left(F_{(2,3593)}, p=0.0119\right)$, the rest of the comparisons were not statistically significant. It is interesting to note that younger mothers (20-24 age class) with two previous children have boys with a lower mean birth weight than the birth weight of their girls (Fig. 2).

Concerning gestation length (Fig. 3, Table III), boys had a shorter gestation than girls; mothers with one or two previous childbirths had also a shorter gestation than primiparous mothers; and older mothers had longer gestation than younger ones.

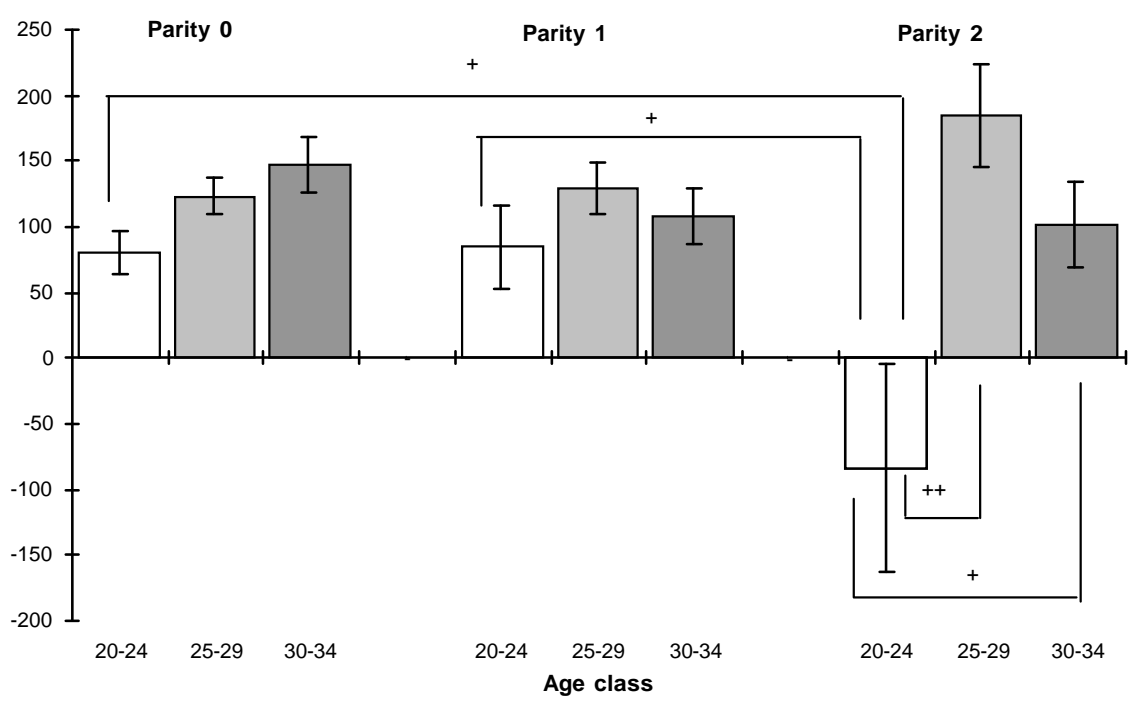

Fig. 2. Extra birth weight of boys (mean \pm SE) of mothers of different parity and age class $\left({ }^{+} p<0.05 ;{ }^{++} p<0.01\right)$. 

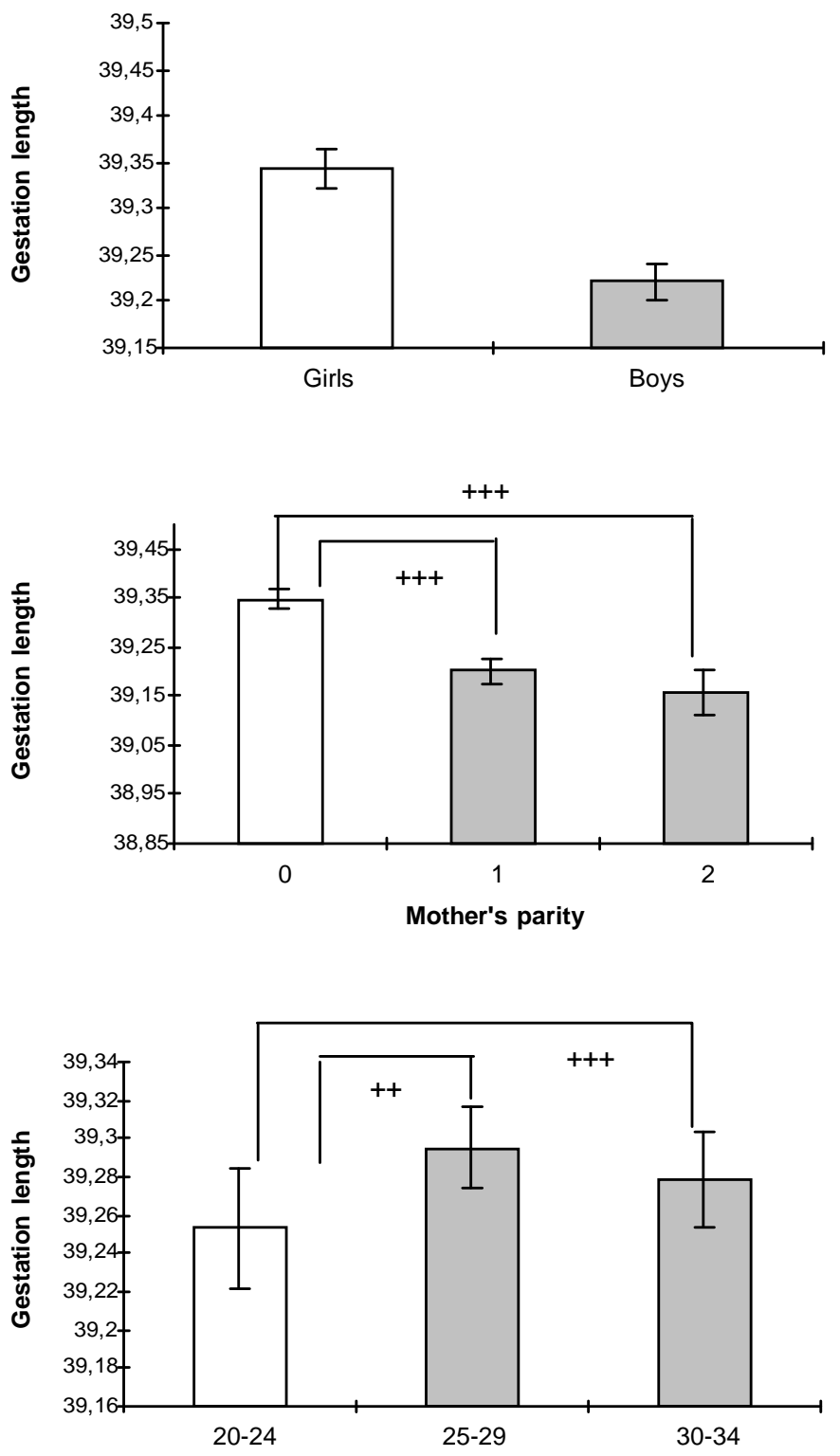

Mother's age class

Fig. 3. Differences in gestation length (mean \pm SE) between a) boys and girls, b) mothers of different parity, and c) mothers of different age class $\left({ }^{++} p<0.01,{ }^{+++} p<0.001\right)$. 
Table III. Analysis of Variance Concerning Gestation Length of Girls and Boys of Mothers of Different Parity and Age Class

\begin{tabular}{lrrrr}
\hline \multicolumn{1}{c}{ Source } & \multicolumn{1}{c}{ df } & Mean square & $F$ value & $p$ palue \\
\hline Sex & 1 & 18.314 & 13.026 & 0.0003 \\
Parity & 2 & 31.424 & 22.351 & 0.0001 \\
Age class & 2 & 9.330 & 6.636 & 0.0013 \\
Sex $\times$ Parity & 2 & 2.241 & 1.594 & 0.2032 \\
Sex $\times$ Age class & 2 & 5.340 & 3.798 & 0.0225 \\
Parity $\times$ Age class & 4 & 5.076 & 3.610 & 0.0060 \\
Sex $\times$ Parity $\times$ Age class & 4 & 3.356 & 2.387 & 0.0488 \\
Residual & 6899 & 1.406 & & \\
\hline
\end{tabular}

The interaction "Sex of the neonate $\times$ Mother's age class" was statistically significant (Table III). Whereas no differences were detected in the gestation length of girls among mothers of different age classes, boys of the younger mothers had shorter gestations than boys of the older ones. Furthermore, although the boys' gestation length was shorter than the girls', neonates of the 25-29 age class mothers did not show statistically significant sex differences in gestation length (Fig.4, Table IV).

The interaction "Mother's parity $\times$ Mother's age class" was also statistically significant (Table III); and although no significant differences in the gestation length were detected among the different age classes of primiparous mothers, in mothers with one or two previous childbirths the gestation length of younger mothers was shorter than that of older mothers (Fig. 5, Table V). Furthermore, in mothers of both the 20-24 and 25-29 age class the gestation length of multiparous mothers was shorter than that of primiparous ones. However, in the 30-34 age class the differences in

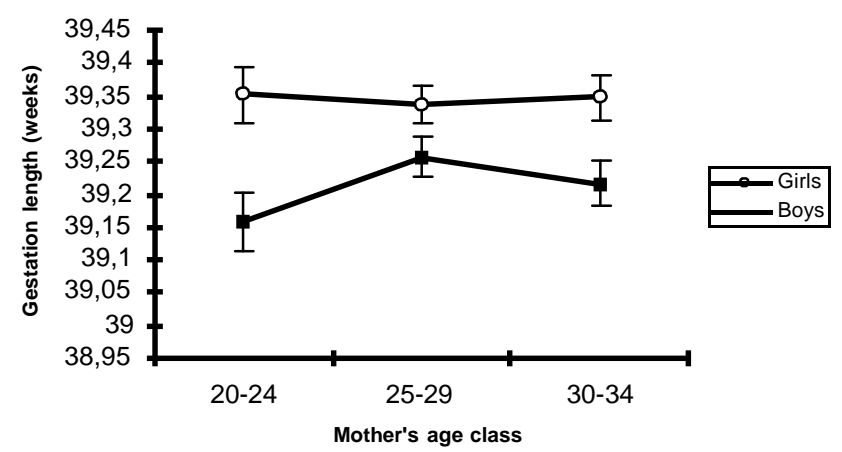

Fig. 4. Differences in gestation length of boys and girls of mothers of different age class. 
Table IV. Comparisons of the Means in the Interaction "Sex of the Neonates $\times$ Mother's Age Class" of the Analysis of Variance Concerning Gestation Length (for all Comparisons df =1)

\begin{tabular}{lrl}
\hline & \multicolumn{1}{c}{$F$} & \multicolumn{1}{c}{$p$} \\
\hline Boys vs. girls (age class 20-24) & 9.261 & $0.0023^{* *}$ \\
Boys vs. girls (age class 25-29) & 0.046 & 0.8307 \\
Boys vs. girls (age class 30-34) & 7.174 & $0.0074^{* *}$ \\
$20-24$ vs. 25-29 (boys) & 22.214 & $0.0001^{* * *}$ \\
$20-24$ vs. 30-34 (boys) & 18.464 & $0.0001^{* * *}$ \\
$25-29$ vs. 30-34 (boys) & 0.600 & 0.4384 \\
$20-24$ vs. 25-29 (girls) & 0.134 & 0.7139 \\
$20-24$ vs. 30-34 (girls) & 1.474 & 0.2248 \\
$25-29$ vs. 30-34 (girls) & 2.234 & 0.1351 \\
\hline
\end{tabular}

${ }^{* *} p<0.01,{ }^{* * *} p<0.001$.

gestation length were statistically significant only in the case of mothers with one previous childbirth, who had a shorter gestation than primiparous ones.

The interaction "Sex of the neonate $\times$ Mother's parity $\times$ Mother's age class' was also statistically significant (Table III). Among mothers with two previous childbirths, those from the 20-24 age class had neonate girls with longer gestation periods than neonate boys $\left(F_{(1,51)}=5.588, p=0.0181\right)$, whereas in mothers older than 24 there was no statistically significant difference in gestation length between girl and boy neonates $\left(F_{(1,228)}=1.115, p=\right.$ 0.2910 , and $F_{(1,412)}=3.251, p=0.0714$, for 25-29 and 30-34 age class mothers respectively).

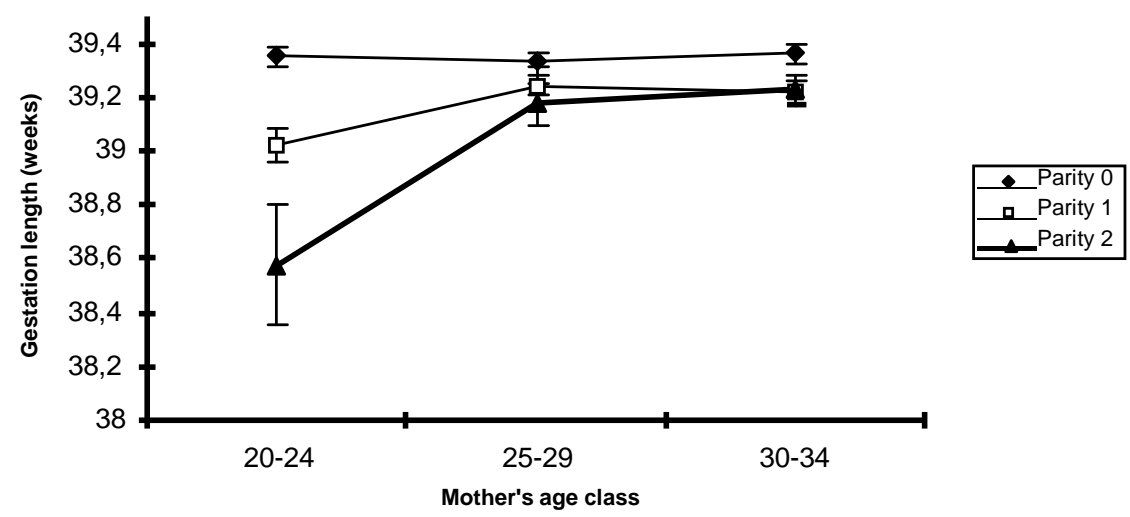

Fig. 5. Differences in gestation length of mothers of different parity and different age class. 
Table V. Comparisons of the Means in the Interaction "Mother's Parity $\times$ Mother's Age Class" of the Analysis of Variance Concerning Gestation Length

\begin{tabular}{|c|c|c|c|}
\hline & & $F$ & $p$ \\
\hline \multirow[t]{3}{*}{ Parity 0} & 20-24 vs. 25-29 Age class & 0.115 & 0.7348 \\
\hline & 20-24 vs. 30-34 Age class & 0.014 & 0.9073 \\
\hline & $25-29$ vs. 30-34 Age class & 0.190 & 0.6633 \\
\hline \multirow[t]{3}{*}{ Parity 1} & 20-24 vs. 25-29 Age class & 9.486 & $0.0021^{* *}$ \\
\hline & 20-24 vs. 30-34 Age class & 7.344 & $0.0067^{* *}$ \\
\hline & 25-29 vs. 30-34 Age class & 0.163 & 0.6867 \\
\hline \multirow[t]{3}{*}{ Parity 2} & $20-24$ vs. $25-29$ Age class & 5.882 & $0.0153^{*}$ \\
\hline & $20-24$ vs. $30-34$ Age class & 8.474 & $0.0036^{* *}$ \\
\hline & $25-29$ vs. $30-34$ Age class & 0.502 & 0.4787 \\
\hline \multirow[t]{3}{*}{ Age class 20-24 } & Parity 0 vs. Parity 1 & 21.785 & $0.0001^{* * *}$ \\
\hline & Parity 0 vs. Parity 2 & 13.691 & $0.0002^{* * *}$ \\
\hline & Parity 1 vs. Parity 2 & 3.024 & 0.0821 \\
\hline \multirow[t]{3}{*}{ Age class 25-29 } & Parity 0 vs. Parity 1 & 4.341 & $0.0372^{*}$ \\
\hline & Parity 0 vs. Parity 2 & 4.366 & $0.0367^{*}$ \\
\hline & Parity 1 vs. Parity 2 & 0.848 & 0.3571 \\
\hline \multirow[t]{3}{*}{ Age class $30-34$} & Parity 0 vs. Parity 1 & 5.964 & $0.0146^{*}$ \\
\hline & Parity 0 vs. Parity 2 & 3.166 & 0.0753 \\
\hline & Parity 1 vs. Parity 2 & 0.025 & 0.8732 \\
\hline
\end{tabular}

\section{DISCUSSION}

The data partially confirm the predictions of the study. The results detect an effect of the mother's age in the sex-biased prenatal investment regardless of mother's parity. No effect of mother's parity was detected independently of their age on the variation in the sex-biased prenatal investment.

Granada mothers in the 25-29 age class provide an extra birth weight to their neonate boys independently of their parity. These mothers are in the peak of fertility and presumably are in better condition than the others of the study sample. In this way, it is plausible to conclude that Granada women follow the prediction of Trivers and Willard's model.

The Trivers and Willard model predicts also that mothers in poor condition would be expected to show a bias in prenatal investment towards girls. In the study sample, younger mothers (20-24 age class) with two previous childbirths gave birth to boys with a lower mean birth weight than the birth weight of their girls. Probably these multiparous younger mothers are in worse condition than the other mothers of the study sample, since they have performed a high reproductive effort in a short period of time, and following the prediction of Trivers and Willard model performed a sex-biased prenatal investment favoring girls.

At this point it is interesting to note that under polygamy or where serial monogamy is permitted, variance in reproductive success is greater 
for men than for women; there is evidence from 104 societies suggesting that in matrilineal as well as patrilineal societies, the reproductive success of high-status sons exceeds the reproductive success of their sisters; parents in good condition invest differentially in boys after birth; and the most powerful predictor of the length of the lactation period was the infant's weight at birth (Bereczkei, 2001; Betzig and Turke, 1986; Dickemann, 1979; Gaulin and Robbins, 1991; Voland, 1984). Furthermore there exists a trade-off between the continued investment in offspring previously produced, and the need to preserve resources for future reproduction. Cualtieri et al. (1984) pointed out that considering that the definition of maternal investment includes costs to future reproduction, in humans antecedent boys diminish the likelihood of subsequent boy births, and antecedent girls enhance the probability of subsequent boys birth.

There is possibly a mechanism that balances the costs supported by the mothers selected to invest more resources in their offspring, and it would be interesting to know how this mechanism is compatible with the selective tendency to favor those offspring in which prenatal investment could be returned in terms of fitness.

Taking into account that the length of gestation is also predictive of birth weight (Zhang and Savitz, 1992), in this study sample the results show that neonate boys had shorter gestation than neonate girls did, although Granada women gave birth to heavier neonate boys than girls as was expected. James (1986) indicated that the probability of conception of a boy is higher in the early and late menstrual cycle because of rapid variation in maternal hormone levels; and in a study of 3,658 births, the proportion of neonate boys was significantly higher in the offspring of women who resumed intercourse 2 days after ovulation, whereas the proportion of neonate girls was higher close to the day of ovulation (Harlap, 1979). Thus, the differences detected in gestation length of boys and girls from Granada mothers cannot be explained by differences in the conception timing. We can think of two possible scenarios. First, differences in the gestation length could derive from variations in intrinsic growth rate of the offspring or in the reproductive efficiency of the mother, and a higher weight offspring would be born earlier because its prenatal growth has finished. Or second, heavier offspring must be born before the prenatal growth has finished because otherwise there would be a higher risk both for the mother in labor and for the offspring. For example, in fallow deer (Dama dama), where male offspring are heavier than female offspring at birth, the level of fetal hemoglobin (a possible index of preterm offspring) was higher in male than in female offspring (Schreiber et al., 1992).

In the study sample, 25-29 age class mothers provide a higher extrabirth weight to their neonate boys than the other mothers, perhaps because in these 25-29 age class mothers the gestation length of their neonate boys 
is longer than in the other age class mothers. This effect might be related to the similarity of the gestation length of neonate boys and girls of the 25-29 age class mothers, who were actually the only mothers who did not show statistically significant sex differences in gestation length. It is interesting to note that within the two previous childbirths mothers, the 20-24 age class are the only mothers whose daughters had longer gestation period than their sons.

These results suggest that Granada mothers, following the prediction of Trivers and Willard's hypothesis, performed a sex-biased prenatal investment by prolonging the gestation period, favoring sons when they were in good condition and daughters when they were in poor condition. This prenatal allocation of resources favoring neonate boys or girls appears to be more related to the mother's age than to the mother's parity, although a lineal relation between mother's age and extra weight in neonates might not be expected.

Future research could explore mechanisms that relate mother's age with their sensitivity to socioecological conditions and with their ability to assume the costs of a future neonate, allowing them to allocate more resources towards their offspring during the prenatal period.

\section{ACKNOWLEDGMENTS}

I want to thank Maria Isabel Pavon, Elena Delgado, Ana Carriazo, and Antonio Camacho, and the Subdirección de Asistencia Especializada del Servicio Andaluz de Salud (Technical Service of the Andalusian Health Service) for their help in obtaining the records. Enrique Collado provided me with enthusiasm, advice, and technical support; I consider extremely valuable the help of Javier Cuervo who stimulated discussions and critical reviews of the manuscript. Juan David Rodriguez contributed to the realization of the figures, and I also wish to thank Alicia Prieto and Mercedes López, because without their cooperation this work would not have been possible. Dr Javier Vico provided me with his comments about the results and with literature about medical findings. Pedro Jordano and Miguel Tejedo suggested changes, which improved my analysis. Finally, I thank Annie Simon and Rita Braza for their support in the worst moments of analysis.

\section{REFERENCES}

Anderson, S. S., and Fedak, M. A. (1987). Grey seal (Halichoerus grypas) energetics: Females invest more in male offspring. Journal of Zoology (London) 211: 667-679.

Bereczkei, T., Hofer, A., and Ivan, Z. (2000). Low birth weight, maternal birth-spacing decisions, and future reproduction. Human Nature 11(2): 183-205. 
Bereczkei, T. (2001). Maternal trade-off in treating high-risk children. Evolution and Human Behavior 22: 197-212.

Betzig, L. L., and Turke, P. W. (1986). Parental investment by sex on Ifaluk. Ethology and Sociobiol. 7: 29-37.

Birgersson, B., and Ekvall, K. (1997). Early growth in male and female fallow deer fawns. Behavioral Ecology 8: 493-499.

Chacon-Puignau, G. C., and Jaffe, K. (1996). Sex ratio at birth deviations in modern Venezuela: The Trivers-Willard effect. Social Biology 43: 257-270.

Cualtieri, C. T., Hicks, R. E., and Mayo, J. P. (1984). Influence of sex of antecedent siblings on the human sex ratio. Life Science 34: 1791-1794.

Daly, M., and Wilson, M. I., (1999). Human evolutionary psychology and animal behaviour. Animal Behaviour 57: 509-519.

Dickemann, M. (1979). Female infanticide, reproductive strategies, and social stratification. A preliminary model. In Chagnon, N., and Irons, W. (eds.), Evolutionary Biology and Human Social Behavior: An Anthropological Perspective, North Scituate, Duxbury, MA, pp. 321-367.

Festa-Bianchet, M. (1988). Nursing behaviour of bighorn sheep, correlates of ewe age, parasitism, lamb age, birthdate and sex. Animal Behaviour 36: 1445-1454.

Fletcher, I. C. (1971). Relationships between frequency of suckling, lamb growth and postpartum oestrus behaviour in ewes. Animal Behaviour 19: 108-111.

Gaulin, S. J. C., and Robbins, C. J. (1991). Trivers-Willard effect in contemporary NorthAmerican society. American Journal Physiology Anthropology 85: 61-69.

Hammel, E. A. (1996). Demographic constraints on population growth of early humans. Human Nature 7: 217-255.

Harlap, S. (1979). Gender of infants conceived on different days of the menstrual cycle. The New England Journal of Medicine 300: 1445-1448.

Hauspie, R. C., Chrzastek-spruch, H., Verleye, G., and Kozlowska, M. A. (1996). Determinants of growth in body length from birth to 6 years of age: A longitudinal study of Dublin children. American Journal of Human Biology 8: 21-29.

James, W. H. (1986). Hormonal control of sex ratio. Journal of Theoretical Biology 118: 427-441.

Lee, P. C., Majluf, P., and Gordon, I. J. (1991). Growth, weaning and maternal investment from a comparative perspective. Journal of Zoology (London) 225: 99-114.

Pélabon, C., Gaillard, J. M., Loison, A., and Portier, C. (1995). Is sex-biased maternal care limited by total maternal expenditure in polygynous ungulates? Behavioral Ecology Sociobiology 37: 311-319.

Rybo, G., Leman, J., and Tibbin, E. (1985). Epidemiology of menstrual blood loss. Serono Symposia Publications 25: 181-193.

San José, C., Braza, F., and Casanova, X. (1997). Reproductive status of mothers affects sexbiased parental investment in humans. Perceptual and Motor Skills 85: 917-918.

Schreiber, A., Braza, F., San José, C., and Aragón, S. (1992). Relationships of foetal haemoglobin level to age of new-born fallow deer (Dama dama). Canadian Journal of Zoology 70: 23642368.

Stein, Z. A. (1985). A woman's age: Child bearing and child rearing. American Journal of Epidemiology 121: 327-342.

Trivers, R. L., and Willard, D. E. (1973). Natural selection of parental ability to vary the sex ratio of offspring. Science 179: 90-92.

Verdú, I., Martín, C., and García, G. (1998). Tablas Españolas de Pesos Neonatales según Edad Gestacional. Barcelona: Laboratorios Menarini, S.A.

Voland, E. (1984). Human sex-ratio manipulation: Historical data from a German parish. Journal of Human Evolution 13: 99-107.

Voland, E. (1998). Evolutionary ecology of human reproduction. Annual Review of Anthropology 27: 347-374.

Zang, J., and Savitz, D. A. (1992). Preterm birth subtypes among blacks and whites. Epidemiology 3: 428-433. 